Pacific Journal of Mathematics

ON RANDOM SOLUTIONS OF VOLTERRA-FREDHOLM 


\title{
ON RANDOM SOLUTIONS \\ OF VOLTERRA-FREDHOLM INTEGRAL EQUATIONS
}

\author{
V. SREE Hari RaO ${ }^{\dagger}$
}

\begin{abstract}
This paper is concerned with the existence, uniqueness and boundedness of random solutions of a random nonlinear mixed integral equation of Volterra-Fredholm type. The main tools for the study are the theory of admissibility of integral operators and the theory of random contractors.
\end{abstract}

1. Introduction. The mathematical description of various processes in physical, biological and engineering sciences gives rise to random or stochastic operator equations. Many applied problems leading to operator equations require the existence and continuity of the inverse operator. In [1], Altman has introduced the notions of inverse differentiability and contractors, which are very useful tools for solving deterministic operator equations in Banach spaces. The subject of random integral operator equations has been the object of numerous investigations in recent years and we refer the reader to the works of Bharucha-Reid [2] and Tsokos and Padgett [12]. Lee and Padgett [5], have developed the theory of random contractors, extending the work of Altman [1] and employed it in the study of random nonlinear Volterra integral equations.

In this paper, we obtain theorems on the existence, uniqueness, boundedness and stability of solutions of the following nonlinear stochastic integral equation of Volterra-Fredholm type

$$
\begin{aligned}
x(t ; \omega)= & f(t ; \omega)+\int_{0}^{t} a(t, s ; \omega) g(s, x(s ; \omega)) d s \\
& +\int_{0}^{\infty} b(t, s ; \omega) h(s, x(s ; \omega)) d s, \quad t \geq 0,
\end{aligned}
$$

where $\omega \in \Omega$, the supporting set of the probability measure space $(\Omega, A, P), x(t ; \omega)$ is the unknown random variable for each $t \in R_{+}=$ $[0, \infty), f(t ; \omega)$ is the stochastic free term defined for $t \in R_{+}, a$ and $b$ are stochastic kernels and $g$ and $h$ are scalar functions defined on $R_{+} \times R$, with $R=(-\infty, \infty)$. The tools used are admissibility theory of integral operators (cf. [4]) and contractor theory.

\footnotetext{
${ }^{\dagger}$ On leave from Osmania University, Hyderabad-500007, India.
} 
We note that the equation (1.1) is a generalization of the equations discussed in $[3,5,6,7,11]$. Our notation and terminology are fairly standard and can be understood by referring to $[5,6]$ and [12]. However, in order to make the paper more self contained, we state briefly the basic definitions that are needed for the main results.

Let $(\Omega, A, P)$ be a complete probability measure space. $C \equiv$ $C\left(R_{+}, L_{2}(\Omega, A, P)\right)$ denotes the space of all continuous functions from $R_{+}$into $L_{2}(\Omega, A, P) \equiv L_{2}$, with the compact open topology. Notice that $C$ is a Fréchet space and contains the second order mean square continuous stochastic processes. For a positive continuous function $u$ on $R_{+}$, we define the space $C_{u}$, to be the space of all continuous functions $x(t ; \omega)$ from $R_{+}$into $L_{2}$ satisfying

$$
\|x(t ; \omega)\|_{L_{2}}=\left(\int_{\Omega}|x(t ; \omega)|^{2} d P(\omega)\right)^{1 / 2} \leq K u(t), \quad t \geq 0,
$$

for some positive constant $K$. Note that $C_{u}$ is a Banach space, with the norm defined by

$$
\|x\|_{C_{u}}=\sup _{t \geq 0}\left\{\|x(t ; \omega)\|_{L_{2}} / u(t)\right\}
$$

The space $C_{1}$ for $u \equiv 1$, includes all the bounded continuous mean square processes on $R_{+}$. We say that a pair $(B, D)$ of Banach spaces in $C$, such that the convergence in $B$ or $D$ implies the convergence in $C$, is said to be admissible with respect to an integral operator $T$, if $T(B) \subset D$.

We shall adopt the following definition from [6].

Definition 1.1. Let $f(t, x ; \omega)$ be a real valued function for $t \in R_{+}$, $x \in R$ and $\omega \in \Omega$ such that $f(t, x(t ; \omega) ; \omega) \in B$ whenever $x(t ; \omega) \in D$. The function $f$ is said to have a bounded integral contractor $\Gamma$ with respect to $(B, D)$ if

(i) for each $t \in R_{+}$and $x \in R$ there exists a bounded linear operator $\Gamma$ from $D$ to $B$ such that $\|\Gamma(t, x)\|$ is continuous in $(t, x)$ and $\|\Gamma(t, x)\| \leq$ $Q$ for some positive constant $Q$; and

(ii) for each $t \in R_{+}$and $x, y \in D$, there exists $\alpha>0$ such that

$$
\begin{aligned}
& \| f(t, x(t ; \omega)+y(t ; \omega)+[T \Gamma(t, x(t ; \omega)) y](t ; \omega) ; \omega) \\
&-f(t, x(t ; \omega) ; \omega)-[\Gamma(t, x(t ; \omega)) y](t ; \omega) \|_{B} \\
& \leq \alpha\|y(t ; \omega)\|_{D} .
\end{aligned}
$$

The constant $\alpha$ is called the contractor constant. 
2. Existence, uniqueness and boundedness of random solutions. In this section, we obtain results on the existence, uniqueness and boundedness of random solutions of (1.1). By a random solution of a stochastic integral equation such as equation (1.1), we shall mean that for each $t \in R_{+}, x(t ; \omega)$ satisfies the equation almost surely. We note that the results of this section are extensions of [6] to (1.1) and are more general than those of [10].

The following hypotheses will be used in the subsequent discussion. Let $B$ and $D$ be Banach subspaces of $C$.

$\left(\mathrm{H}_{1}\right) f(t ; \omega) \in D$.

$\left(\mathrm{H}_{2}\right)$ The pair $(B, D)$ is admissible with respect to the operator $T$ : $C \rightarrow C$, defined by

$(T x)(t ; \omega)=\int_{0}^{t} a(t, s ; \omega) x(s ; \omega) d s+\int_{0}^{\infty} b(t, s ; \omega) x(s ; \omega) d s, \quad t \geq 0$.

$\left(\mathrm{H}_{3}\right) x(t ; \omega) \rightarrow g(t ; x(t ; \omega))$ are continuous mappings from $C$ into $C$, such that $x(t ; \omega) \in D$ implies $g(t, x(t ; \omega))$ and $h(t, x(t ; \omega)) \in B$.

$\left(\mathrm{H}_{4}\right)$ For each $\lambda>0$, there exists a $\delta_{1}>0$ such that

$$
\|g(t, x(t ; \omega))-g(t, y(t ; \omega))\|_{B} \leq \lambda\|x(t ; \omega)-y(t ; \omega)\|_{D}
$$

whenever $\|x(t ; \omega)\|_{D},\|y(t ; \omega)\|_{D} \leq \delta_{1}$.

$\left(\mathrm{H}_{5}\right)$ For each $\eta>0$, there exists a $\delta_{2}>0$ such that

$$
\|h(t, x(t ; \omega))-h(t, y(t ; \omega))\|_{B} \leq \eta\|x(t ; \omega)-y(t ; \omega)\|_{D}
$$

whenever $\|x(t ; \omega)\|_{D},\|y(t ; \omega)\|_{D} \leq \delta_{2}$.

THEOREM 2.1. Let $\left(\mathrm{H}_{1}\right),\left(\mathrm{H}_{2}\right)$ and $\left(\mathrm{H}_{3}\right)$ hold. Also suppose that the functions $g$ and $h$ have bounded integral contractors $\Gamma_{1}$ and $\Gamma_{2}$ with contractor constants $\alpha$ and $\beta$ respectively. Then there exists a random solution to (1.1) provided $K(\alpha+\beta)<1$ where $K=\|T\|$. Furthermore, the random solution is unique, if the integral equation

$$
\begin{aligned}
y(t ; \omega) & +\int_{0}^{t} a(t, s ; \omega) \Gamma_{1}(s, x(s ; \omega)) y(s ; \omega) d s \\
+ & \int_{0}^{\infty} b(t, s ; \omega) \Gamma_{2}(s, x(s ; \omega)) y(s ; \omega) d s=z(t ; \omega)
\end{aligned}
$$

where $x(t ; \omega), z(t ; \omega) \in D$, has a solution in $D$. 
Theorem 2.2. Let $\left(\mathrm{H}_{1}\right)$ and $\left(\mathrm{H}_{2}\right)$ hold, in which $B=D=C_{u}$ and $u$ and $G$ are positive continuous functions on $R_{+}$, such that

$$
\begin{aligned}
\int_{0}^{t}[\|a(t, s ; \omega)\|+\|b(t, s ; \omega)\|] u(s) d s & \\
& +\int_{t}^{\infty}\|b(t, s ; \omega)\| u(s) d s \leq M G(t),
\end{aligned}
$$

for $t \in R_{+}$, where $M$ is a positive constant. In addition, assume that for each $t \in R_{+}$and $x, y \in C_{u}$, there exist bounded linear operators $\Gamma_{1}(t, x) \equiv$ $\Gamma_{1}$ and $\Gamma_{2}(t, x) \equiv \Gamma_{2}$ such that

$$
\begin{aligned}
& \| g(t, x(t ; \omega)+y(t ; \omega) \\
& \left.\quad+\int_{0}^{t} a(t, s ; \omega)\left(\Gamma_{1} y\right)(s ; \omega) d s\right)-g(t, x(t ; \omega))-\left(\Gamma_{1} y\right)(t ; \omega) \|_{L_{2}} \\
& \leq \alpha\|y(t ; \omega)\|_{L_{2}}
\end{aligned}
$$

and similarly

$$
\begin{aligned}
& \| h(t, x(t ; \omega)+y(t ; \omega) \\
& \left.\quad+\int_{0}^{\infty} b(t, s ; \omega)\left(\Gamma_{2} y\right)(s ; \omega) d s\right)-h(t, x(t ; \omega))-\left(\Gamma_{2} y\right)(t ; \omega) \|_{L_{2}} \\
& \leq \beta\|y(t ; \omega)\|_{L_{2}} .
\end{aligned}
$$

Then, there exists a random solution $x(t ; \omega)$ of $(1.1)$ such that $E|x(t ; \omega)|^{2}$ $\leq \lambda^{2} G^{2}(t), t \geq 0$, where $\lambda>0$ is a constant, provided $K(\alpha+\beta)<1$.

The proofs of Theorems 2.1 and 2.2 may be easily constructed, following those of Theorems 3.1, 3.2 and 3.3 of [6]. We omit the details.

THEOREM 2.3. Suppose that the conditions $\left(\mathrm{H}_{1}\right)-\left(\mathrm{H}_{5}\right)$ hold. Then, if there exists a number $\varepsilon_{0}>0$ such that for $0<\varepsilon \leq \varepsilon_{0}$,

$$
\|f(t ; \omega)\|_{D}+K\|g(t, 0)\|_{B}+K\|h(t, 0)\|_{B}<\delta \varepsilon,
$$

for some fixed $\delta \in(0,1)$ and $K=\|T\|$, then there exists a unique random solution $x(t ; \omega)$ of $(1.1)$ in $D$ and further $\|x(t ; \omega)\| \leq \varepsilon$.

Theorem 2.3 extends Theorem 2.2 [10, p. 314] by dropping the condition $g(t, 0) \equiv h(t, 0) \equiv 0$ and its proof is a direct application of Banach's contraction mapping principle. Also it may be viewed as a stochastic stability result of solutions of (1.1). For, given $\varepsilon>0$, there exists $\delta(\varepsilon)>0$ such that $\|x(t ; \omega)\|_{D}<\varepsilon$ for all $t \geq 0$, with probability one, whenever $\|f(t ; \omega)\|_{D}$ is sufficiently small with probability one. 
THEOREM 2.4. Assume the following:

(i) $f(t ; \omega) \in C_{1}$.

(ii) $\left(C_{1}, C_{1}\right)$ is admissible with respect to the nonlinear random operator defined by

$$
\begin{aligned}
(N x)(t ; \omega)= & \int_{0}^{t} a(t, s ; \omega) g(s, x(s ; \omega)) d s \\
& +\int_{0}^{\infty} b(t, s ; \omega) h(s, x(s ; \omega)) d s .
\end{aligned}
$$

(iii) There exist positive numbers $A_{0}$ and $B_{0}$ such that

$\sup _{t \geq 0} \int_{0}^{t}\|a(t, s ; \omega)\| d s \leq A_{0}<\infty$ and $\sup _{t \geq 0} \int_{0}^{\infty}\|b(t, s ; \omega)\| d s \leq B_{0}<\infty$.

(iv) On the set $S_{\gamma}=\left\{x(t ; \omega) \in C_{1}:\|x(t ; \omega)\|_{C_{1}} \leq \gamma\right\}, g$ and $h$ satisfy Lipschitz conditions in $L_{2}$-norm with constants $\lambda$ and $\mu$, respectively.

Then there exists a unique random solution $x^{*}(t ; \omega)$ of $(1.1)$ in $C_{1}$ such that $E\left|x^{*}(t ; \omega)\right|^{2} \leq \gamma^{2}$ for all $t \geq 0$, provided $\left(\lambda A_{0}+\mu B_{0}\right)<1$ and $\|f(t ; \omega)\|_{C_{1}} \leq \gamma\left[1-\left(\lambda A_{0}+\mu B_{0}\right)\right]$.

It is easy to see that Theorem 2.4 is a combination of the results on random Volterra equations [11] and on random Fredholm equations [8]. However in these papers the hypothesis (ii) is replaced by $\left(\mathrm{H}_{2}\right)$ in which the operator is linear. We may also apply Theorem 3.4 of [5], by noticing that the identity random operator $I(\omega)$ is a bounded random contractor for the operator $U: S_{\gamma} \rightarrow C_{1}$ given by $(U(\omega) x)(t ; \omega)=x(t ; \omega)-f(t ; \omega)$ - $(N(\omega) x)(t ; \omega)$. Also, the hypothesis on the Volterra kernel in Theorem 2.4 is weaker than the corresponding condition (i) of Theorem 3.4 [6].

3. Boundedness results and examples. In this section, assuming existence, some additional theorems and examples on the boundedness of solutions under different conditions than those in $\$ 2$, are presented. These theorems extend some of the results of [3] and [7].

We consider the following equation

$$
\begin{aligned}
x(t ; \omega)= & f(t ; \omega)+\int_{0}^{t} a(t, s ; \omega) g(x(s ; \omega)) d s \\
& +\int_{0}^{\infty} b(t, s ; \omega) h(x(s ; \omega)) d s, \quad t \geq 0,
\end{aligned}
$$

and list the following conditions:

$\left(\mathrm{H}_{6}\right) f(t ; \omega)$ is bounded on $R_{+} \times \Omega$. 
$\left(\mathrm{H}_{7}\right) \sup _{t \geq 0} \int_{0}^{t}|a(t, s ; \omega)| d s \leq A_{0}<\infty$ with probability one, and with probability one, $\sup _{t \geq 0} \int_{0}^{\infty}|b(t, s ; \omega)| d s \leq B_{0}<\infty$.

$\left(\mathrm{H}_{8}\right) g, h \in \mathcal{C}(-\infty, \infty)$, where $\mathcal{C}$ denotes the class of continuous functions from $R \rightarrow R$.

$\left(\mathrm{H}_{9}\right)$ With probability one, $a(t ; \omega) \leq 0$ for $0 \leq t<\infty$ and $a^{\prime}(t ; \omega) \geq 0$ on $0<t<\infty$.

$\left(\mathrm{H}_{10}\right) \int_{0}^{\infty}\left|f^{\prime}(t ; \omega)\right| d t<\infty$, with probability one.

In $\left(\mathrm{H}_{9}\right)$ and $\left(\mathrm{H}_{10}\right)$ "', denotes the derivative with respect to $t$, for each $\omega$.

$\left(\mathrm{H}_{11}\right) \quad g \in \mathcal{C}(-\infty, \infty), \quad G(x)=\int_{0}^{x} g(u) d u \rightarrow \infty$ as $|x| \rightarrow \infty$, and $|g(x)| \leq K[1+G(x)],|x|<\infty$, for some constant $K>0$.

THEOREM 3.1. Let $\left(\mathrm{H}_{6}\right),\left(\mathrm{H}_{7}\right)$ and $\left(\mathrm{H}_{8}\right)$ hold. Further suppose that with probability one

(3.2) $\left(\sup _{t \geq 0} \int_{0}^{t}|a(t, s ; \omega)| d s\right) \limsup _{|x| \rightarrow \infty}\left|\frac{g(x)}{x}\right|<1$, and with probability one

$$
\left(\sup _{t \geq 0} \int_{0}^{\infty}|b(t, s ; \omega)| d s\right) \limsup _{|x| \rightarrow \infty}\left|\frac{h(x)}{x}\right|<1 .
$$

Then every random solution of (3.1) is bounded on $0 \leq t<\infty$, with probability one.

Proof. Let $x(t ; \omega)$ be a random solution of (3.1) for $t \geq 0$. In view of the condition (3.2), we can choose $K_{1}, K_{2}$ sufficiently large, and $\rho_{1}, \rho_{2}>0$ with $\rho_{1}+\rho_{2}<1$ and such that, with probability one

$$
\begin{gathered}
\left(\sup _{t \geq 0} \int_{0}^{t}|a(t, s ; \omega)| d s\right)|g(x(t ; \omega))|<\rho_{1}|x(t ; \omega)|, \\
\text { for }|x(t ; \omega)| \geq K_{1} \text { and with probability one, } \\
\left(\sup _{t \geq 0} \int_{0}^{\infty}|b(t, s ; \omega)| d s\right)|h(x(t ; \omega))|<\rho_{2}|x(t ; \omega)|, \\
\text { for }|x(t ; \omega)| \geq K_{2} .
\end{gathered}
$$

Let $K=\max \left\{K_{1}, K_{2}\right\}$.

Define

$$
I_{1}=\{u:|x(u ; \omega)|>K\} \quad \text { and } \quad I_{2}=\{u:|x(u ; \omega)| \leq K\}, \quad \omega \in \Omega .
$$

From $\left(\mathrm{H}_{6}\right)$, there exists $M>0$ such that $|f(t ; \omega)| \leq M$ on $0 \leq t<\infty$, $\omega \in \Omega$. Since $g$ and $h$ are continuous, there exist $L_{1}, L_{2}>0$ such that 
$|g(x(u ; \omega))| \leq L_{1}$ and $|h(x(u ; \omega))| \leq L_{2}$ for $|x(u ; \omega)| \leq K$, that is for $u \in I_{2}$. Now from (3.1) and (3.3), we have

$$
\begin{aligned}
x(t ; \omega)= & f(t ; \omega)+\int_{I_{1}} a(t, s ; \omega) g(x(s ; \omega)) d s \\
& +\int_{I_{2}} a(t, s ; \omega) g(x(s ; \omega)) d s+\int_{I_{1}} b(t, s ; \omega) h(x(s ; \omega)) d s \\
& +\int_{I_{2}} b(t, s ; \omega) h(x(s ; \omega)) d s .
\end{aligned}
$$

That is,

$$
\begin{aligned}
|x(t ; \omega)| \leq & M+\left(\rho_{1} / \sup _{t \geq 0} \int_{0}^{t}|a(t, s ; \omega)| d s\right) \int_{I_{1}}|a(t, s ; \omega)||x(s ; \omega)| d s \\
& +L_{1} \int_{I_{2}}|a(t, s ; \omega)| d s+\left(\rho_{2} / \sup _{t \geq 0} \int_{0}^{\infty}|b(t, s ; \omega)| d s\right) \\
& \times \int_{I_{1}}|b(t, s ; \omega)||x(s ; \omega)| d s+L_{2} \int_{I_{2}}|b(t, s ; \omega)| d s, \\
\leq M+ & \rho_{1} \sup _{s \in I_{1}, s \leq t}|x(s ; \omega)|+L_{1} A_{0}+\rho_{2} \sup _{s \in I_{1}, s \leq t}|x(s ; \omega)|+L_{2} B_{0} .
\end{aligned}
$$

Since this is valid for every $t \geq 0$, we have, with probability one

$$
\sup _{0 \leq t \leq T}|x(t ; \omega)| \leq M+L_{1} A_{0}+L_{2} B_{0}+\left(\rho_{1}+\rho_{2}\right) \sup _{0 \leq s \leq T}|x(s ; \omega)|,
$$

for every $T>0$ and since $0<\rho_{1}+\rho_{2}<1$, we see that

$$
\sup _{0 \leq t \leq T}|x(t ; \omega)| \leq \frac{M+L_{1} A_{0}+L_{2} B_{0}}{1-\left(\rho_{1}+\rho_{2}\right)} .
$$

Since this bound is independent of $t$, we see that

$$
\sup _{0 \leq t \leq \infty}|x(t ; \omega)| \leq \frac{M+L_{1} A_{0}+L_{2} B_{0}}{1-\left(\rho_{1}+\rho_{2}\right)}
$$

with probability one and this completes the proof of the theorem.

Corollary 3.2. Assume $\left(\mathrm{H}_{6}\right),\left(\mathrm{H}_{7}\right)$ and $\left(\mathrm{H}_{8}\right)$ and that

$$
\limsup _{|x| \rightarrow \infty}\left|\frac{g(x)}{x}\right|=\limsup _{|x| \rightarrow \infty}\left|\frac{h(x)}{x}\right|=0 .
$$

Then, every solution of (3.1) is bounded on $R_{+}$. 
Since the hypothesis (3.4) implies (3.2), the proof follows from Theorem 3.1.

The next result is also a boundedness result and is specialized to the random integral equation of Volterra type, given by

$$
x(t ; \omega)=f(t ; \omega)+\int_{0}^{t} a(t-s ; \omega) g(x(s ; \omega)) d s, \quad t \geq 0 .
$$

TheOREM 3.3. Assume $\left(\mathrm{H}_{9}\right),\left(\mathrm{H}_{10}\right)$ and $\left(\mathrm{H}_{11}\right)$. Then every solution of (3.5) satisfies $\sup _{0 \leq t<\infty}|x(t ; \omega)|<\infty$, with probability one.

The deterministic analogue of (3.5) has been considered by Londen [7]. Following the proof of Theorem 2 [7] and using the Lemma 6.1 [2, p. 192], the proof of Theorem 3.3 may be completed.

Now consider the equation (3.1), in which $b(t, s ; \omega)=0$ for $0 \leq s$, $t<\infty$ and $\omega \in \Omega$ and $a(t, s ; \omega) \equiv a(t-s ; \omega)$. Then Theorems 3.1 and 3.3 provide sufficient conditions for the boundedness of all solutions of (3.5). It is interesting to note that the two sets of conditions are in general different, which can be seen from the following examples.

EXAMPLE 3.4. Consider the following equation

$$
x(t ; \omega)=f(t ; \omega)+\int_{0}^{t} a(t, s ; \omega) g(x(s ; \omega)) d s,
$$

$t \geq 0$ and $\omega \in \Omega \subset R_{+}$, where

$$
\begin{gathered}
f(t ; \omega)=e^{-t / 3-\omega}, \quad t \geq 0, \quad \omega \in \Omega, \quad a(t, s ; \omega)=e^{-(t-s+2 \omega / 3)}, \\
0 \leq s \leq t<\infty, \quad \omega \in \Omega \quad \text { and } \quad g(x)=-\frac{2}{3} x^{1 / 3} \quad \text { for } x \in R .
\end{gathered}
$$

Now by Theorem 3.1 all solutions of (3.6) are bounded on $R_{+}$. Indeed, the random function $x(t ; \omega)=e^{-(t+\omega)}, 0 \leq t<\infty$ and $\omega \in \Omega$ is a bounded solution of (3.6). It may be noted that Theorem 3.3 cannot be applied to (3.6) as all its hypotheses are not satisfied.

EXAMPLE 3.5. All the solutions of the nonlinear random equation

$$
x(t ; \omega)=f(t ; \omega)+\int_{0}^{t} a(t-s ; \omega) g(x(s ; \omega)) d s
$$

$t \geq 0$, and $\omega \in \Omega \subset R_{+}$, where $f(t ; \omega)=1 /(1+\omega), a(t ; \omega) \equiv-1$, for $t \in R_{+}$and $\omega \in \Omega$, and $g(x)=x^{2}$ on $R$, are bounded by Theorem 3.3. In 
particular $x(t ; \omega)=1 /(1+t+\omega), 0 \leq t<\infty$, and $\omega \in \Omega$ is a bounded solution of (3.7). It is easy to see that the conditions $\left(\mathrm{H}_{7}\right)$ and (3.2) of Theorem 3.1 are not satisfied.

The author is grateful to the referee for many valuable suggestions.

\section{REFERENCES}

[1] M. Altman, Inverse differentiability contractors and equations in Banach spaces, Studia Math., 46 (1973), 1-15.

[2] A. T. Bharucha-Reid, Random Integral Equations, Academic Press, New York, 1972.

[3] F. Brauer, On a nonlinear integral equation for population growth problems, SIAM J. Math. Anal., 6 (1975), 312-317.

[4] C. Corduneanu, Integral Equations and Stability of Feedback Systems, Academic Press, New York, 1973.

[5] A. C. H. Lee and W. J. Padgett, Random contractors and the solutions of random nonlinear equations, Nonlinear Analysis, Theory, Meth. Appl., 1 (1977), 175-185.

[6] _ A random nonlinear integral equation in population growth problems, J. Integral Equations, 2 (1980), 1-9.

[7] S. O. Londen, On the solutions of a nonlinear Volterra equation, J. Math. Anal. Appl., 39 (1972), 564-573.

[8] W. J. Padgett and C. P. Tsokos, On a stochastic integral equation of the Fredholm type, Z. Wahr. Verw. Geb., 23 (1972), 22-31.

[9] A new stochastic formulation of a population growth problem, Math. Bio. Sci., 17 (1973), 105-120.

[10] V. Sree Hari Rao, Topological methods for the study of nonlinear mixed stochastic integral equations, J. Math. Anal. Appl., 74 (1980), 311-317.

[11] C. P. Tsokos, On a stochastic integral equation of Volterra type, Math. Systems Theory, 3 (1969), 222-231.

[12] C. P. Tsokos and W. J. Padgett, Random Integral Equations with Applications to Life Sciences and Engineering, Academic Press, New York, 1974.

Received November 4, 1981 and in revised form July 14, 1982. Research supported by grants from NSERC-Canada.

THE UNIVERSITY OF AlBERTA

Edmonton, Alberta T6G 2G1, Canada 



\title{
PACIFIC JOURNAL OF MATHEMATICS EDITORS
}

\author{
Donald BabBitT (Managing Editor) \\ University of California \\ Los Angeles, CA 90024 \\ Hugo Rossi \\ University of Utah \\ Salt Lake City, UT 84112 \\ C. C. Moore and Arthur Ogus \\ University of California \\ Berkeley, CA 94720
}

\author{
J. DugundiI \\ Department of Mathematics \\ University of Southern California \\ Los Angeles, CA 90089-1113 \\ R. FINN and H. SAMELSON \\ Stanford University \\ Stanford, CA 94305
}

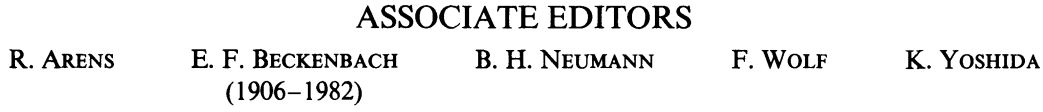

\section{SUPPORTING INSTITUTIONS}

UNIVERSITY OF ARIZONA
UNIVERSITY OF BRITISH COLUMBIA
CALIFORNIA INSTITUTE OF TECHNOLOGY
UNIVERSITY OF CALIFORNIA
MONTANA STATE UNIVERSITY
UNIVERSITY OF NEVADA, RENO
NEW MEXICO STATE UNIVERSITY
OREGON STATE UNIVERSITY

\author{
UNIVERSITY OF OREGON \\ UNIVERSITY OF SOUTHERN CALIFORNIA \\ STANFORD UNIVERSITY \\ UNIVERSITY OF HAWAII \\ UNIVERSITY OF TOKYO \\ UNIVERSITY OF UTAH \\ WASHINGTON STATE UNIVERSITY \\ UNIVERSITY OF WASHINGTON
}

The Supporting Institutions listed above contribute to the cost of publication of this Journal, but they are not owners or publishers and have no responsibility for its content or policies.

Mathematical papers intended for publication in the Pacific Journal of Mathematics should be in typed form or offset-reproduced (not dittoed), double spaced with large margins. Please do not use built up fractions in the text of the manuscript. However, you may use them in the displayed equations. Underline Greek letters in red, German in green, and script in blue. The first paragraph must be capable of being used separately as a synopsis of the entire paper. In particular it should contain no bibliographic references. Please propose a heading for the odd numbered pages of less than 35 characters. Manuscripts, in triplicate, may be sent to any one of the editors. Please classify according to the scheme of Math. Reviews, Index to Vol. 39. Supply name and address of author to whom proofs should be sent. All other communications should be addressed to the managing editor, or Elaine Barth, University of California, Los Angeles, California 90024.

There are page-charges associated with articles appearing in the Pacific Journal of Mathematics. These charges are expected to be paid by the author's University, Government Agency or Company. If the author or authors do not have access to such Institutional support these charges are waived. Single authors will receive 50 free reprints; joint authors will receive a total of 100 free reprints. Additional copies may be obtained at cost in multiples of 50 .

The Pacific Journal of Mathematics is issued monthly as of January 1966. Regular subscription rate: $\$ 132.00$ a year (6 Vol., 12 issues). Special rate: $\$ 66.00$ a year to individual members of supporting institutions.

Subscriptions, orders for numbers issued in the last three calendar years, and changes of address should be sent to Pacific Journal of Mathematics, P.O. Box 969, Carmel Valley, CA 93924, U.S.A. Old back numbers obtainable from Kraus Periodicals Co., Route 100, Millwood, NY 10546.

The Pacific Journal of Mathematics ISSN 0030-8730 is published monthly by the Pacific Journal of Mathematics at P.O. Box 969, Carmel Valley, CA 93924. Application to mail at Second-class postage rates is pending at Carmel Valley, California, and additional mailing offices. Postmaster: Send address changes to Pacific Journal of Mathematics, P. O. Box 969, Carmel Valley, CA 93924.

PUBLISHED BY PACIFIC JOURNAL OF MATHEMATICS, A NON-PROFIT CORPORATION

Copyright $(1983$ by Pacific Journal of Mathematics 


\section{Pacific Journal of Mathematics}

Vol. 108, No. $2 \quad$ April, 1983

Enrique Atencia and Francisco Javier Martin-Reyes, The maximal ergodic Hilbert transform with weights $\ldots \ldots \ldots \ldots \ldots \ldots \ldots \ldots \ldots . \ldots 257$

Bruce Blackadar, The regular representation of local affine motion

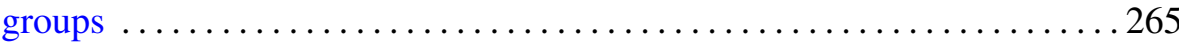

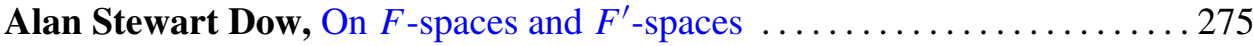

Yoshifumi Kato, On the vector fields on an algebraic homogeneous space . . 285

Dmitry Khavinson, Factorization theorems for different classes of analytic functions in multiply connected domains $\ldots \ldots \ldots \ldots \ldots \ldots \ldots \ldots 295$

Wei-Eihn Kuan, A note on primary powers of a prime ideal . . . . . . . . 319

Benjamin Michael Mann and Edward Yarnell Miller, Characteristic classes for spherical fibrations with fibre-preserving free group

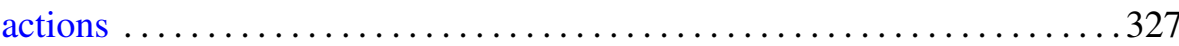

Steven Alan Pax, Appropriate cross-sectionally simple four-cells are flat . . . 379 R. K. Rai, On orthogonal completion of reduced rings ................ 385

V. Sree Hari Rao, On random solutions of Volterra-Fredholm integral

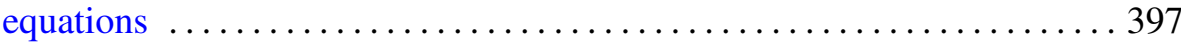

Takeyoshi Satō, Integral comparison theorems for relative Hardy spaces of solutions of the equations $\Delta u=P u$ on a Riemann surface $\ldots \ldots \ldots . .407$

Paul Sydney Selick, A reformulation of the Arf invariant one $\bmod p$ problem and applications to atomic spaces

Roelof Jacobus Stroeker, Reduction of elliptic curves over imaginary quadratic number fields

Jacob Towber, Natural transformations of tensor-products of representation-functors. I. Combinatorial preliminaries

James Chin-Sze Wong and Abdolhamid Riazi, Characterisations of amenable locally compact semigroups 